\title{
Commentary: Transforming an Economy
}

\author{
Brian Easton
}

This paper responds to the minister's paper by providing a context in which the government's economic transformation agenda operates. It argues that it is not a plan but a framework for the coherent organising of government's evolving involvement in the economy. To illustrate how this occurs the latter part of the paper focuses on some Auckland issues, which are yet to be resolved, and mentions some of the other areas for further development.

Perhaps the greatest current puzzle about the New Zealand economy is why it is not growing more quickly. It stagnated from 1985 to 1993 as a result of the liberalisation policies of the time, even though the rest of the world grew strongly. At the beginning of this period New Zealand was a fraction above the OECD average measured by GDP per capita; eight years later it was $15 \%$ or so below. The New Zealand economy has since grown slightly faster than the world economy, mainly by utilising the reserves of labour - evident in lower unemployment and higher labour force participation. But productivity growth has been low - lower than the long-term trend. If it continues to be low, economic growth will be low since the potential labour force reserves are now largely exhausted.

We might have expected significant productivity gains as the economy recovered from the shock of the market liberalisation policies, so that, once through the stagnation phase, it would have grown more rapidly until it returned to its pre-liberalisation track. But of that there is no sign. Why not? Any answer is even the more puzzling because export prices have been largely favourable, and an unusually large external (current account) deficit probably accelerated the growth rate. But the boost given by these factors to economic growth and productivity is not evident in the statistics either.

Did the liberalisation policies irrecoverably damage the economy? What about the intensificationist thesis that more extreme liberalisation is needed, as if repeating failures of the past will generate success in the future? In the last seven years the Labour-led government has chosen a different strategy to that of its immediate predecessors, while maintaining some of the central elements of the liberalisation programme.

The current government's Growth and Innovation Framework (GIF) specifically included a 'stable macroeconomic framework', an 'open and competitive microeconomy' and a 'globally connected economy'. A 'highly skilled population' and a 'solid research, development and innovation framework' had already been adopted by the previous, National government in the late 1990s. (New in the GIF was a 'modern cohesive society' and 'sound environmental management'.) Meanwhile, some of the more extremist policy stands have been reversed, replaced by a pragmatic response to public and private ownership, a less conflictual approach to industrial relations, with a broadening and deepening of the social partnership arrangements, and a willingness to tackle monopoly. The government has also given priority to dealing with the public sector and social deficits, even though the additional spending has given it less room for tax cuts.

Less noticed is the government's commitment to sectoral engagement, dealing with each sector on a pragmatic rather than ideologically uniform basis. Many industrial sectors do not require much engagement, but, where they do, the government has got involved.

The approach involves a rejection both of the implicit model of the market liberalisers of the 1980s, and also of much of the recent research paradigms of various agencies (including the Treasury). They treat economic output as a homogeneous single commodity, as if the composition of output does not matter. That makes no sense for the medium term because sectors grow at different rates, while many undergo significant 
Figure 1: Regional Labour Productivity (2003)

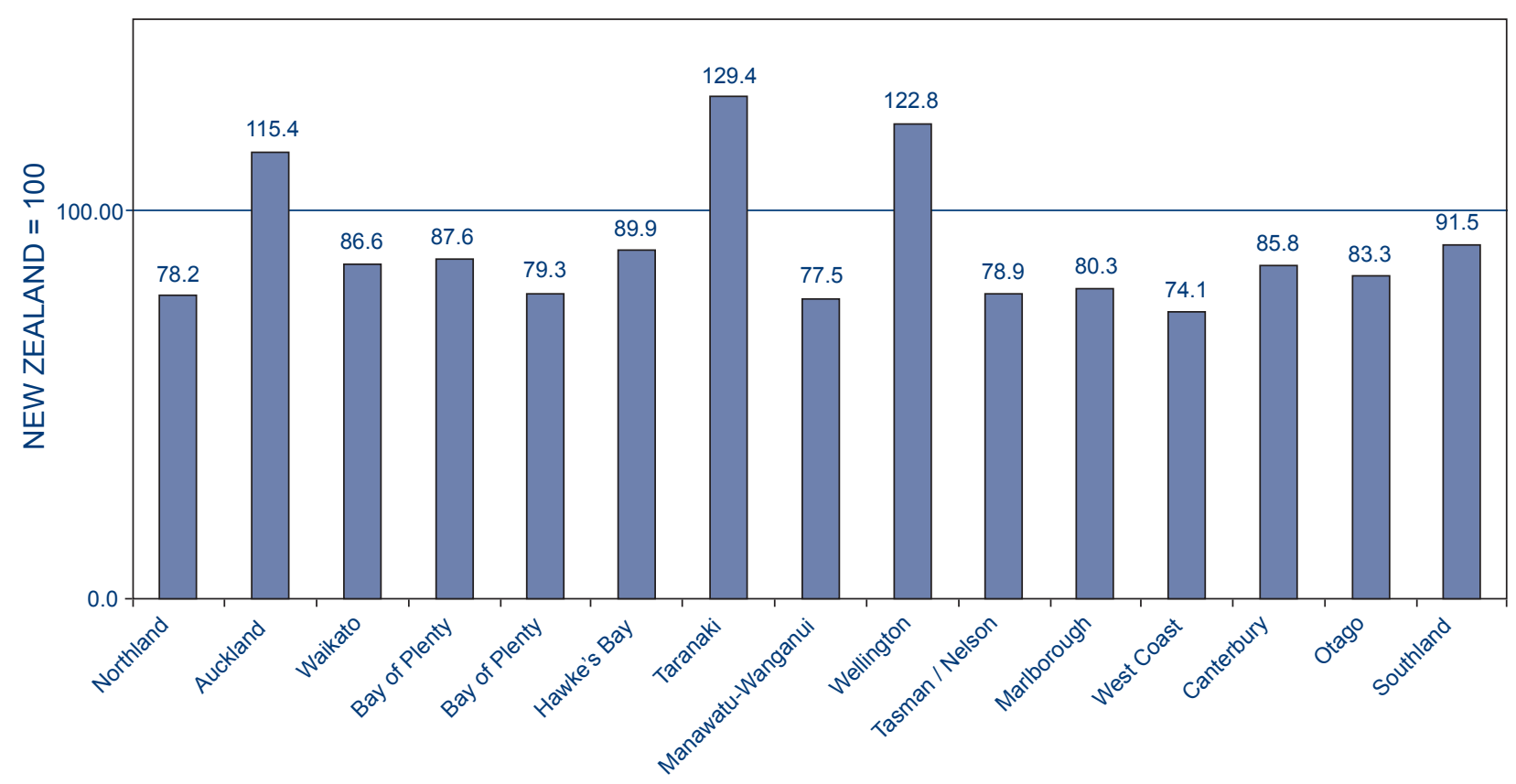

internal change. Sectoral engagement rejects the single commodity approach.

The rest of this article will focus on the Auckland strategy, the government's most interesting sectoral engagement. Figure 1, based on recently released estimates of regional GDP, gives a measure of productivity per worker by region (using full-time employment equivalents). There is considerable variation. With the highest productivity is Taranaki, reflecting the contribution from its (depleting) hydrocarbon fields and capital intensive petrochemical plants. Not far behind is the Wellington region with its highly paid public servants.

(Any ranking by region reflects sectoral composition, rather than some inherent merit of the region. Nor do the figures indicate the relative regional incomes, because they ignore tax and social security flows and (net) payments to asset owners outside the region. Moreover, if, say, the price of exports is higher (or the exchange rate lower), the relativities of rural regions would rise, without changes in real productivity.)

The third (and only other) region with above-average productivity is Auckland, strong in the business and transport sectors, and weak in primary production. It is not especially strong in manufacturing, and is slightly below average in tourism and education, health and community services. The data emphasise Auckland as
New Zealand's 'gateway' city and headquarters city. Is it a global city?

The government has two major immediate concerns. Auckland has poorly functioning city governance and severe infrastructural problems - most evidently in its internal transport network. The government is tackling them - politically courageously for the first, and fiscally courageously for the second. Given the size of the infrastructural deficit, significant gains are a decade out. Effective local authority reform may take longer.

These are necessary and urgent reforms, but they are not sufficient. Not far from the government's thinking is a structural change strategy which began 70 years ago. The Depression exposed New Zealand's overdependence on the pastoral sector and on the British export market. There has been much diversification since, into other primary industries and post-farm gate processing, and into other export markets. The strategy of import-substituting industrialisation which began in the late 1930s unravelled in the 1980s, although it led to some export manufacturing.

In a globalising world, New Zealand import substitution faces tradeable goods and services from low wage countries (notably China for manufactures and India for services). It may be that Auckland is not a particularly significant manufacturer because its import-substituting 
manufacturing has wound down. Some of the rural regions are more intensive manufacturers because the processing of primary products cannot be so easily carried out offshore.

Other rich economies face similar challenges. They (often reluctantly) offshore routine activities and instead focus on the innovation, design and development stages of tradeable manufacturing and services, and on production so sophisticated that it takes a highly skilled workforce, not yet available in poorer countries. Can New Zealand? Such high-productivity production occurs in large, vibrant urban centres, as a result of agglomeration effects - economies of scale for clusters of industries. Is Auckland large enough to be such a centre?

The facts are that Auckland is about the 350th city in the world in population size, and 150th in terms of regional GDP. Some economists think it is big enough to generate the required economies of agglomeration (it is certainly big enough to generate the congestion). Others think it too small.

My view comes from considering the biotech industry. There is no 'US' biotech industry. Rather, there are vigorous industries in about a dozen American urban agglomerations, each of which is bigger than Greater Auckland.

So what Auckland biotech area should we think about? Surely we should add Hamilton, which is making a significant contribution to the Greater Auckland biotech industry. The motorway between the two cities is to be completed this year. It makes sense to see the two cities as a single economic unit.

If Hamilton is a part of Greater Auckland, where else is? There is an obvious node at the isthmus, with secondary nodes at Hamilton, Tauranga, Whangarei and Rotorua. But in the US just-in-time businesses are an overnight trucking away from their customers. In which case the entire North Island can be 'Greater Auckland' if the transport network is sufficiently integrated. (Air links could add Christchurch and Dunedin for light valuable products, while broadband connections bring in anywhere for electronic transportable services.)

Despite the pride the government takes in doubling spending on roading, it is probably not enough, while the rail system upgrade seems to have got lost. We need a national goal of a four-lane highway network connecting the seven major urban centres by, say, 2030, with an effective freight railway system to accompany it.

At the moment local Auckland is too concerned with its own problems to think about Greater Auckland. (An impatient outsider might think their focus is on 'Petty Auckland'.) Even the central government is so involved with the isthmus's problems that it has not yet thought enough about the wider issue. It may be forced to, since the rest of the country will not take kindly to the apparent privileging of Auckland, not only with political attention and infrastructural spending: its education, health and recreational sectors also need upgrading to global city standards. The New Zealand economy cannot succeed without Auckland succeeding, but the reverse is equally true.

What about the South Island? My guess is that there is probably a case for developing Christchurch as a second hub, not in competition with Auckland but as a complement. Outside Christchurch and Dunedin, the South Island will remain primary product export (including tourism) focused, as will much of the rural North Island. But broadband may generate service business for those who prefer the rural lifestyle.

The last few paragraphs go beyond the current economic transformation agenda. The government is incrementalist in its policy approach, in part because it eschews the big thinking of Rogernomics, but also because it is embarking on a much more intellectually complex policy development than market liberalisation, with (probably) fewer able advisers, given the damage Rogernomics did to the government bureaucracy. But I shall not be surprised if eventually it adopts a strategy of an integrated North Island with Auckland as a hub, and a South Island hub at Christchurch.

One could write similarly on other policy areas which need further development:

- private saving requires further boosting;

- the innovation strategy needs to pay more attention to international technology transfer;

- the energy strategy is only on the way to sustainability after oil production peaks (and needs to be integrated with the transport and climate change strategies);

- the funding arrangements for tertiary education continue to distort and inhibit that sector's performance; 
- the tax system is neither optimal nor equitable;

- the implications for social cohesion remain unaddressed.

Until recently I would have grumbled about the lack of connection between economic transformation and national identity. However, the minister's paper indicates that this challenge is beginning to be addressed.

Other sectoral strategy issues will arise as the economic transformation agenda evolves. (I have a concern about our not effectively utilising our water resources, while the success or failure of the Doha Round will present considerable challenges to our trade negotiators, to exporters and, ultimately, to the economy as a whole.)

That is the point of the economic transformation agenda. It is not a fixed plan, but a framework by which to organise the government involvement in the structural evolution of the New Zealand economy. The evolution has always been occurring, even though it was unnecessarily inhibited by the policies of the 1980s and 1990s. The involvement should not slow our economic growth rate. It may even accelerate it.

Brian Easton is an independent scholar who researches, writes and teaches in economics, social statistics, public policy and New Zealand studies. His book Globalisation and the Wealth of Nations, the research for which was sponsored by the Marsden Fund, will be published this year. He currently holds a Claude McCarthy Fellowship to work on an economic history of New Zealand. He is a member of the Growth and Innovation Advisory Board, which is the government's chief private sector adviser on the Growth and Innovation Framework and the Economic Transformation Agenda. It should be noted that the views expressed in this article are not those of the board, and may not reflect the views of other board members. He can be contacted at the Economic and Social Trust on New Zealand, 18 Talavera Terrace, Wellington, www.eastonbh.ac.nz.

\section{SPECIAL MEASURES TO} REDUCE ETHNIC DISADVANTAGE IN NEW ZEALAND An Examination of Their Role

An Institute of Policy Studies publication by Paul Callister

Policies designed to achieve greater equality between ethnic groups have been variously described as 'positive discrimination', 'preferential treatment', affirmative action', 'measures to ensure equality' and 'special measures'.

Special Measures To Reduce Ethnic Disadvantage In New Zealand: An Examination of Their Role considers the measurement of ethnicity and the causes of ethnic disadvantage, the nature and history of special measures in New Zealand, and the strengths and weaknesses of such measures. It concludes with reflections on the circumstances under which such mesures are likely to be most effective, as well as politically acceptable.

Published - February 2007

Format - A5 Paperback, pp 132

ISBN - 1-877347-16-7

Price $-\$ 25.00$ (including P\&P within

New Zealand)

To have a copy of and an invoice sent to you, please email, phone, fax or mail your order to:

Institute of Policy Studies

Victoria University of Wellington

Email ipos@vuw.ac.nz

Telephone +64 44635307

Fax +64 44637413

P0 Box 600, Wellington

New Zealand 